\title{
Correction to: Publication of Abstracts and Full Papers from the International Conference on the Origin of Life, San Diego, 2017
}

\author{
Alan W. Schwartz ${ }^{1}$ \\ Published online: 12 September 2018 \\ (C) Springer Nature B.V. 2018
}

\section{Correction to: Orig Life Evol Biosph \\ https://doi.org/10.1007/s11084-017-9549-y}

Plans for the publication of Abstracts from the meeting have been cancelled. However, manuscripts for full papers will still be considered for publication in OLEB.

These manuscripts should be submitted in the usual way via the journal's home page (https://link.springer.com/journal/11084) and should conform to the OLEB style (see Instructions for Authors). They should indicate on the first page that they were presented at the conference.

The online version of the original article can be found at https://doi.org/10.1007/s11084-017-9549-y

Alan W. Schwartz

originseditor@outlook.com

1 Radboud University Nijmegen, Nijmegen, The Netherlands 